\title{
Studi Pemanfaatan Limbah Padat Industri Pengolahan Minyak Kelapa Sawit Spent Bleaching Earth sebagai Pengganti Agregat pada Campuran Beton
}

\author{
Moch. Luqman Ashari, Denny Dermawan \\ Program Studi Teknik Pengolahan Limbah, Politeknik Perkapalan Negeri Surabaya \\ E-mail: denny.dermawan@ppns.ac.id
}

\begin{abstract}
Abstrak
Industri pengolahan minyak kelapa sawit menghasilkan limbah padat berupa Spent Bleaching Earth (SBE).SBE mengandung senyawa kimia yaitu $\mathrm{SiO}_{2}$ mencapai 83,05\%. $\mathrm{SiO}_{2}$ atau debu silica dapat mengakibatkan silicosis jika tersebar ke udara dan sering terhiruo oleh pekerja. Di sisi lain $\mathrm{SiO}_{2}$ adalah salah satu material penyusun semen portland, sehingga perlu untuk diadakan riset tentang pengolahan dan pemanfaaatan limbah SBE sebagai bahan campuran pembuatan beton. Limbah SBE dimanfaatkan untuk menggantikan agregat halus dengan komposisi $0 \%, 10 \%, 20 \%, 30 \%$, dari $40 \%$ dari jumlah total agregat halus. Pengujian yang dilakukan adalah uji kuat tekan, setting time, dan Toxicity Characteristic Leaching Procedur (TCLP). Metode mix design menggunakan SNI 03-2834-2000 debgan f'c 28,5 MPa dan slump $12 \pm 2 \mathrm{~cm}$. Hasil dari penelitian ini menunjukkan jika beton dengan campuran limbah SBE yang mencapai kuat tekan perencanaan adalah 10\% SBE sebesar 34,16 MPa dan 20\% SBE sebesar 29,06 MPa. Berdasarkan hasil uji TCLP, konsentrasi logam berat dalam beton dengan campuran $10 \%$ SBE berada dibawah baku mutu TCLP. Hasil ini membuktikan secara ilmiah jika beton dengan campuran $10 \%$ SBE layak secara teknis dan lingkungan.
\end{abstract}

Kata kunci: spent bleaching earth, concrete, fine aggregate,compressive strength, TCLP

\begin{abstract}
Palm oil refineryfactory has solid waste byproduct called Spent Bleaching Earth (SBE). SBE consists of some chemical compounds and one of them is $\mathrm{SiO} 2$ up to $83,05 \%$. SiO2 or silica fume can cause silicosis if it is exposed to the atmosphere and frequently inhaled by the workers. On the other hand, $\mathrm{SiO} 2$ is one of the material composition of Portland cement. Thus, it is necessary to conduct a research about the utilization of SBE. as a concrete mixture. SBE is utilized as fine aggregate substitution by the composition of $0 \%, 10 \%, 20 \%, 30 \%$, and $40 \%$ of the total amount of fine aggregate. The conducted tests are compressive strength, setting time, and TCLP. The method used for mix design is SNI 03-2834-2000 with f'c 28,5 MPa and slump $12 \pm 2 \mathrm{~cm}$. This research shows that concretes with SBE substitution which achieve the planned compressive strength are 10\% SBE with 34,16 MPa and $20 \%$ SBE with 29,06 MPa. Based on the TCLP test, the concentration of heavy metal substances in 10\% SBE are below the standard. Thus, it is scientifically proven to conclude that concrete with $10 \%$ SBE is technically proper and safe for the environment.
\end{abstract}

Keywords: spent bleaching earth, concrete, fine aggregate,compressive strength, TCLP.

\section{PENDAHULUAN}

Salah satu limbah hasil proses produksi dari industri pengolahan minyak kelapa sawit yang jumlahnya cukup besar adalah limbah padat berupa Spent Bleaching Earth (SBE). Berdasarkan Lampiran I PP No. 101 Tahun 2014, SBE termasuk dalam daftar limbah B3 dari sumber spesifik khusus dengan kategori bahaya 2 . Industri menyediakan TPS di area pabrik dan melimpahkan pengelolaan limbah tersebut ke vendor pengelolaan Limbah B3.

Limbah SBE tersusun dari beberapa komposisi kimia yang salah satunya berupa $\mathrm{SiO}_{2}$ dengan prosentasemencapai 83,05\%. $\mathrm{SiO}_{2}$ atau biasa dikenal dengan debu silika berpotensi menyebabkan penyakit silikosis, apabila terlalu sering dihirup oleh pekerja. Di sisi lain, $\mathrm{SiO}_{2}$ merupakan salah satu senyawa penyusun semen Portland.

Kurniasari (2008); Silitonga (2008); Syamsiah (2008); Li dkk. (2014) telah mempelajari konsentrasi unsur-unsur logam berat pada limbah dapat diturunkan dengan metode solidifikasi. Pada penelitian lain Asavapisit dkk. (2001); Mohamed (2011); Susanti (2011), Dewi dkk. (2016), Dermawan dan Ashari (2016) telah dijelaskan penambahan debu silika dapat meningkatkan nilai kuat tekan campuran beton.

Berdasarkan uraian permasalahan tersebut, serta mengacu pada tingginya kadar $\mathrm{SiO}_{2}$ dan besarnya kuantitas limbah 
SBE hasil produksi, maka perlu diadakan riset tentang pengolahan dan pemanfaaatan limbah SBE sebagai bahan campuran pembuatan beton.

Penelitian ini akan menggunakan limbah $S B E$ sebagai pengganti agregat halus pada campuran beton. Parameter yang digunakan untuk menguji kelayakan limbah SBE sebagai pengganti agregat halus pada campuran pembuatan beton pada penelitian ini adalah uji kuat tekan dan uji TCLP.

Penelitian ini akan memvariasikan campuran limbah SBEbsebesar 10\%, 20\%, $30 \%$, dan $40 \%$. Metode mix design yang digunakan yaitu SNI 03-2834-2000 dengan f'c 28,5 MPa dan nilai slump $12 \pm 2 \mathrm{~cm}$. Produk beton akan di uji kelayakan teknis dan lingkungan. Kelayakan teknis di uji melalui pengujian tekanan dilakukan dengan menggunakan alat universal testing machine kapasitas 2000 kN, sedangkan kelayakan lingkungan di uji melalui pengujian toksisitas beton dengan metode Toxicity Characteristic Leaching Procedure (TCLP).

\section{METODOLOGI PENELITIAN}

Langkah-langkah yang dilakukan dalam penelitian Studi Pemanfaatan Limbah Padat Industri Pengolahan Minyak Kelapa Sawit Spent Bleaching Earth Sebagai Pengganti Agregat Halus pada Campuran Beton Adalah sebagai berikut:

1. Mengidentifikasikan potensi pemanfaatan limbah SBE sebagai bahan campuran beton.

2. Mempersiapkan alat-alat yang digunakan dalam penelitian ini. Persiapan meliputi mempersiapkan cetakan silinder dengan ukuran $15 \mathrm{~cm}$ x $30 \mathrm{~cm}$ sebanyak 30 buah, mesin uji kuat tekan, dan peralatan uji TCLP.

3. Memeriksa bahan-bahan yang akan digunakan meliputi:

a) Pemilihan agregat kasar. Agregat kasar yang dipilih berasal dari paserpan dengan ukuran 5-10 mm dan $10-20 \mathrm{~mm}$.

b) Pemilihan agregat halus dari limbah $S B E$. Agregat halus dipilih dengan cara diayak dengan menggunakan ayakan $4.75 \mathrm{~mm}, 2.36 \mathrm{~mm}, 1.19 \mathrm{~mm}$, $0.60 \mathrm{~mm}, \quad 0.30 \mathrm{~mm}, \quad 0.15 \mathrm{~mm}$, $0.075 \mathrm{~mm}$. Pemilihan agregat halus ini disesuaikan dengan standart PBI 1971.

c) Perencanaan komposisi $S B E$. Komposisi yang digunakan ada lima. Tujuan dari adanya variasi ini adalah untuk mengetahui komposisi yang terbaik guna menghasilkan kuat tekan yang sesuai dengan SNI 032834-2000. Adapun komposisi yang akan digunakan adalah sebagaimana terdapat pada Tabel 1.

Tabel 1. Variasi Komposisi Campuran SBE dengan Agregat Halus

\begin{tabular}{ccc}
\hline Komposisi & SBE & Agregat Halus \\
\hline Blangko/Kontrol & $0 \%$ & $100 \%$ \\
Komposisi 1 & $10 \%$ & $90 \%$ \\
Komposisi 2 & $20 \%$ & $80 \%$ \\
Komposisi 3 & $30 \%$ & $70 \%$ \\
Komposisi 4 & $40 \%$ & $60 \%$ \\
\hline
\end{tabular}

d) Pembuatan benda uji. Benda uji dibuat dengan cara mencampurkan semen, agregat kasar, komposisi agregat halus dan limbah SBE yang yelah ditentukan, beserta air. Semua bahan dicampur dengan rata lalu isikan campuran beton yang akan dibuat benda ujinya ke dalam cetakan secara bertahap 3 (tiga) lapis. Masing-masing ditumbuk sebanyak 25 kali. Beton dikeringkan dengan cara di angin-anginkan dan tandai masing-masing sampel.

e) Perendaman. Kegiatan dilakukan pada bak-bak perendaman yang terhindar dari matahari dengan tujuan mengurangi penguapan dan menghindari keretakan pada beton. Perendaman dilakukan selama 7 dan 28 hari.

f) Pengujian kuat tekan. Kegiatan dilakukan menggunakan alat universal testing machine. Pembebenan dilakukan hingga benda uji retak/ hancur sehingga didapatkan kekuatan maksimal dari beton

g) Pengujian kadar logam berat. Kadar logam berat dalam benda uji dianalisis konsentrasinya dengan uji TCLP. Kegiatan ini bertujuan untuk mengetahui tingkat bahaya benda uji bagi lingkungan sesuai dengan PP 101 tahun 2014.

\section{HASIL DAN PEMBAHASAN}

Perencanaan campuran beton pada penelitian ini menggunakan metode SNI 032834-2000 yang telah diadopsi dari metode DOE 1975. 


\section{Analisa Kuat Tekan Beton}

Pengujian kuat tekan beton dilakukan setelah beton mengalami perawatan pada umur 28 hari. Hal ini ditunjukkan pada Grafik 1 pada SNI 03-2834-2000. Uji kuat tekan bertujuan untuk mengontrol komposisi bahan penyusun terutama penambahan limbah SBE sudah memenuhi mutu yang direncanakan pada 28 hari yaitu beton dengan kuat tekan karakteristik 28,5 MPa.

Hasil uji Kuat Tekan Beton dengan campuran limbah SBE pada Umur 7 dan 28 Hari dapat dilihat pada Gambar 1 berikut.

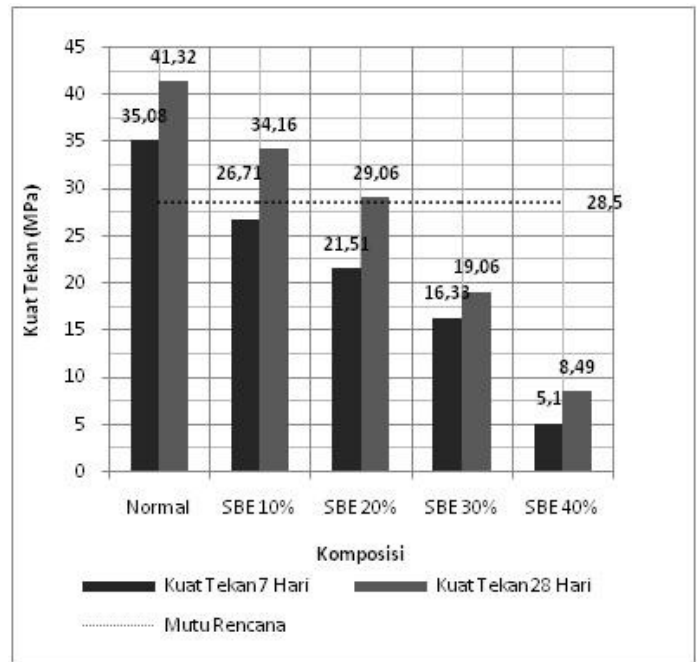

Gambar 1. Grafik Kuat Tekan Beton Campuran Limbah SBE pada Umur 7 dan 28 Hari (Sumber: Hasil Uji Kuat Tekan, 2017)

Berdasarkan data hasil uji kuat tekan umur 28 hari yang ditunjukkan pada Gambar 1, benda uji beton normal, campuran SBE $10 \%$, dan campuran SBE $20 \%$ telah memenuhi mutu yang direncanakan pada uji kuat tekan 28 hari yaitu 28,5 MPa dengan kuat tekan masingmasing sebesar 41,32 MPa, 34,16 MPa, dan $29,06 \mathrm{MPa}$. Beton dengan komposisi SBE $10 \%, 20 \%, 30 \%$, dan $40 \%$ mengalami penurunan kuat tekan terhadap beton normal berturut-turut sebesar 17,32\%; $29,67 \%$; 53,87\%; dan $79,45 \%$. Hal ini menunjukan bahwa penggunaan limbah $S B E$ justru mengakibatkan penurunan kuat tekan disebabkan terjadinya penurunan perekatan. Hal ini disebabkan limbah SBE memiliki permukaan lebih kasar dibanding dengan pasir dan semen sehingga, limbah $S B E$ tidak bisa maksimal dalam pengikatan maupun mengisi celah pori pori pada beton.

\section{Analisa Uji TCLP}

Pengujian TCLP (Toxicity Characteristic Leaching Procedure) dilakukan pada beton campuran $S B E$ yang memiliki hasil uji kuat tekan terbaik sesuai dengan mutu yang direncanakan ( $f^{\prime} \mathrm{c}=28,5 \mathrm{MPa}$ ). Pada penelitian ini, beton campuran $S B E$ yang memiliki kuat tekan terbaik adalah beton campuran SBE $10 \%$ dengan nilai kuat tekan pada umur 28 hari sebesar 34,16 MPa.

Pengujian TCLP dilakukan untuk mengetahui berapa konsentrasi mineral logam berbahaya yang terkandung pada benda uji setelah dilakukan solidifikasi material limbah menjadi campuran beton. Hasil pengujian TCLP pada beton SBE 10\% dapat dilihat pada Tabel 2.

Tabel 2. Hasil Uji TCLP untuk Beton dengan Campuran Limbah SBE 10\%

\begin{tabular}{ccc}
\hline Parameter & $\begin{array}{c}\text { Hasil Uji } \\
(\mathrm{ppm})\end{array}$ & $\begin{array}{c}\text { Baku Mutu } \\
(\mathrm{ppm})\end{array}$ \\
\hline $\mathrm{Hg}$ & 0,0006 & 0,05 \\
$\mathrm{~Pb}$ & 0,0274 & 0,5 \\
$\mathrm{Cd}$ & 0,0135 & 0,15 \\
$\mathrm{Cr}^{6+}$ & 0,0008 & 2,5 \\
$\mathrm{Cu}$ & 0,0244 & 10 \\
$\mathrm{Ni}$ & 0,0120 & 3,5 \\
$\mathrm{Zn}$ & 8,837 & 50,0 \\
\hline
\end{tabular}

Berdasarkan Tabel 2 yang mengacu pada baku mutu pada Lampiran IV PP No. 101 Tahun 2014, konsentrasi mineral logam berbahaya pada beton SBE $10 \%$ secara keseluruhan berada di bawah baku mutu. Dengan demikian, beton SBE $10 \%$ dinyatakan layak teknis dan layak lingkungan apabila digunakan sebagai material konstruksi.

\section{KESIMPULAN}

Beton dengan campuran SBE yang memenuhi kuat tekan rencana (28,5 MPa) adalah beton SBE $10 \%$ dan SBE $20 \%$ dengan nilai kuat tekan masing-masing sebesar 34,16 MPa dan 29,06 MPa. Hasil pengujian TCLP menujukkan bahwa beton SBE $10 \%$ dapat dinyatakan aman dari segi lingkungan.

\section{DAFTAR PUSTAKA}

Asavapisit, S., Nanthamontry, W., Polprasert, C. 2001. Influence of Condensed Silica Fume on the Properties of Cement-Based Solidified Wastes. Cement and Concrete Research, Vol. 31, pp. 1147-1152.

Aswad, N. 2013. Penggunaan Limbah Las Karbit Dan Fly ash Sebagai Bahan Subtitusi Semen Pada Paving Block. Metropilar, Vol. 11

Badan Standarisasi Nasional, 2000, Standart Nasional Indonesia nomor 03-2834-2000 tentang Tata Cara 
Pembuatan Rencana Campuran Baton Normal. Jakarta: Republik Indonesia.

Badan Standarisasi Nasional, 2000, Standart Nasional Indonesia nomor 03-2847-2002 tentang Tata Cara Perhitungan Struktur Beton Untuk Bangunan Gedung. 2002. Jakarta: Republik Indonesia.

Budiarto. 2007. Pengaruh Limbah Karbit dan Fly Ash Terhadap Kekuatan Mortar. Bachelor Thesis, Universitas Kristen Petra

Building Code Requirement for Structural Concrete (ACl 318-08) and commentary. 2008. U.S.A: American Concrete Institute.

Connor, R.J. 1990. Chemical Fixation and Solidification of Hazardous Waste. Mc. Graw-Hill Inc. Unite States.

Dermawan, D., Ashari, M.L. 2016. Studi Komparasi Kelayakan Teknis Pemanfaatan Limbah B3 Sandblasting terhadap Limbah B3 Sandblasting dan Fly Ash sebagai Campuran Beton. Seminar Nasional Maritim, Sains dan Teknologi Terapan 21 November 2016. Surabaya: Politeknik Perkapalan Negeri Surabaya.

Dewi, N. R., Dermawan, D., Ashari, M.L. 2016. Studi Pemanfaatan Limbah B3 Karbit dan Fly Ash sebagai Bahan Campuran Beton Siap Pakai (BSP) (Studi Kasus: PT. Varia Usaha Beton). Jurnal Teknik Lingkungan UNDIP Vol.13 / No.1 / Maret 2016. Semarang: Universitas Diponegoro.

Departemen Pekerjaan Umum dan Tenaga Listrik. 1971. Peraturan Beton Bertulang Indonesia N.I-2. Bandung: Republik Indonesia.

Departemen Pemukiman dan Prasarana Wilayah, Badan Penelitian dan Pengembangan. 2002. Metode, Spesifikasi, dan Tata Cara bagian 3. Beton, Semen, Pengkerasan Beton Semen. Jakarta.
Duggal, S.K. 2008. Bulding Materials, Third Revised Edition. New Age International Publishes.

Gunawan., S. F. 2011. Pemanfaatan Limbah Abu Terbang yang Ramah Lingkungan Sebagai Bahan Stabilisasi Tanah Dasar. Pusbalitbang Jalan dan Jembatan.

Guven, O., Ozdemir, O., Karaagaclioglu, I. E., Celik, M.S. 2014. Surface Morphologies and Floatability of Sand-Blasted Quartz Particles. Minerals Engineering, Vol. 70, pp. 1$7 .$.

Hazardous Substance Fact Sheet. 2009. United States: New Jersey Departemen of Health.

Madany, I. M., Raveendran, E. 1992. Leachability of Heavy Metals from Copper Blasting Grit Waste. Waste Management \& Research, Vol. 10, 87-91

Madany, I. M., Al-Sayed, M. H., Raveendran, E. 1991. Utilization of Copper Blasting Grit Waste as A Contruction Material. Waste Management, Vol. 11, pp 35-40.

Makaratat, N. e. 2010. Effects of Calcium Carbide Residue-Fly Ash Binder on Mechanical Properties of Concrete. Journal of Materials in Civil.

Muthoharoh, I 2012. Self Healing Capability Beton Dengan Fly Ash Sebagai Pengganti Sebagian Semen Ditinjau Dari Workability, Kuat Tekan, dan Permeabilitas. Universitas Sebelas Maret.

Ogunbode, E. B. 2013. Feat of Blended Sorghum Husk Ash-Calcium Carbide Sludge Cment Laterized Concrete. Nigeria: School of Environmental Technology.

Peraturan Pemerintah Nomor 101 Tahun 2014 Tentang Pengelolaan Limbah Bahan Berbahaya dan Beracun. 2014. Jakarta: Republik Indonesia.

Setyawan, D. 2012. Pemanfaatan Beton Ringan Dari Agregat Pumice Dengan Penambahan Fly ash Sebagai Pengganti Beton Biasa Untuk Struktur 